\title{
Doğu Akdeniz Bölgesinde Farklı Sıra Aralıklarının Pamuk Bitkisinin (Gossypium hirsutum L.) Verim ve Sulama Suyu Miktarına Etkisi
}

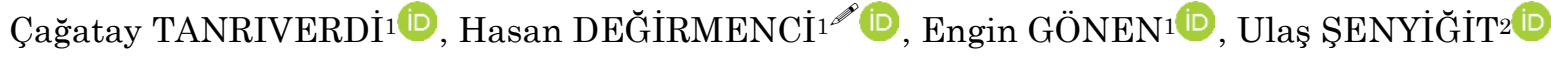

${ }^{1}$ Kahramanmaraş Sütçü İmam Üniversitesi Ziraat Fakültesi Biyosistem Mühendisliği Bölümü, Kahramanmaraş, ${ }^{2}$ Süleyman Demirel Üniversitesi Ziraat Fakültesi Tarımsal Yapılar ve Sulama Bölümü, Isparta

$\triangle$ : degirmenci@ksu.edu.tr

\section{ÖZET}

Bu çalışmada, 3 farklı sıra aralığının $(50,70$ ve $90 \mathrm{~cm})$ pamuk verimi ve uygulanan sulama suyu miktarına etkisinin belirlenmesi amaçlanmıştır. Deneme, 2013 yılında Kahramanmaraş Doğu Akdeniz Geçit Kuşağı Tarımsal Araştırma Enstitüsü arazisinde tesadüfi bloklar deneme desenine göre 3 tekerrürlü olarak yürütülmüştür. Uygulanan sulama suyu miktarlarına göre, en yüksek sulama suyu miktarı $622 \mathrm{~mm}$ ile $70 \mathrm{~cm}$ sıra aralığına sahip konuya uygulanırken, en düşük sulama suyu miktarı $555 \mathrm{~mm}$ ile 90 cm aralığına sahip konuya ait olduğu ölçülmüştür. Araştırma sonuçlarına göre, en yüksek kütlü verim değeri $70 \mathrm{~cm}$ sıra aralığına sahip konularda $595.6 \mathrm{kgda}^{-1}$ olarak, en düşük kütlü verim değeri ise $90 \mathrm{~cm}$ sıra aralığına sahip konularda $378.6 \mathrm{kgda}^{-1}$ olarak elde edilmiştir.

\section{DOI:10.18016/ksudobil.287802}

\author{
Makale Tarihçesi \\ Geliş : 29.03.2017 \\ Kabul : 22.05.2017
}

\author{
Anahtar Kelimeler \\ Sulama suyu miktarı, \\ pamuk, \\ sira aralığı
}

\section{Araştırma Makalesi}

\section{Conditions of Kahramanmaras Different Row Spacing on the cotton plant (Gossypium hirsutum L.) Effect of Irrigation Water Yields and Applied Amount}
ABSTRACT
In this study, three different row spacing $(50,70,90 \mathrm{~cm})$ were In this study, three different row spacing $(50,70,90 \mathrm{~cm})$ were evaluated for their effect on cotton yield and the amount of applied irrigation water. Trial was conducted as random blocks with 3 replications in the Eastern Mediterranean Gateway Zone Agricultural Research Institute, Kahramanmaras, in 2013. According to the irrigation water applied, the maximum amount of irrigation water of $622 \mathrm{~mm}$ applied to $70 \mathrm{~cm}$ row spacing treatment whereas the lowest of 555 $\mathrm{mm}$ to $90 \mathrm{~cm}$ intervals. According to research results, the highest seed yield was obtained from $70 \mathrm{~cm}$ row spacing as $595.6 \mathrm{~kg}^{-1}$ and the lowest from $90 \mathrm{~cm}$ row spacing as $378.6 \mathrm{~kg}^{-1}$.

\author{
Article History \\ Received: 19.04.2017 \\ Accepted: 27.05.2017
}

\author{
Keywords \\ Amount of irrigation water, \\ cotton, \\ row spacing
}

\section{Research Article}

To Cited :Tanrıverdi Ç, Değirmenci H, Gönen E, Şenyiğit U 2018. Doğu Akdeniz Bölgesinde Farklı Sıra Aralıklarının Pamuk Bitkisinin (Gossypium Hirsutum L.) Verim ve Sulama Suyu Miktarına Etkisi KSÜ Tarim ve Doğa Derg 21(2):185190, DOI:10.18016/ksudobil.287802.

\section{GíRIŞ}

Pamuk bitkisi dünyada Pamuk Kuşağ 1 (Cotton Belt) olarak isimlendirilen ve kuzey yarım küre içinde $37^{\circ} \mathrm{N}$ ve Asya Ukrayna'da $47^{\circ} \mathrm{N}$ ile Güney yarıkürede $35^{\circ} \mathrm{S}$ enlem dereceleri arasında kalan alanda yetişmektedir. Akdeniz'de; Antalya, Çukurova, Hatay, Kahramanmaraş, Güneydoğu Anadolu'da; Gaziantep, Diyarbakır, Şanlıurfa, Mardin ile batıda Ege'de; Muğla, Denizli, Aydın, İzmir, Balıkesir ve Çanakkale illeri uygun pamuk yetiştirme alanları olarak belirlenmiştir (Gürel ve ark., 2000). Pamuk, hem ülkemiz hem de dünya tarım, sanayi ve ticaretinde önemli yere sahip bitkilerden birisidir. Son 45 yılda pamuk tüketimi \%140 artarak 25 milyon tona ulaşmış ve geçmiş yıllar ile kıyaslandığında bu güne kadarki en yüksek tüketim miktarı olmuştur (Özüdoğru ve Çakanyıldırım, 2006). Pamuğun ülkemizdeki ekim alanı 542 bin ha, üretimi 955 bin ton ve verimi ise 17.6 kg/ha'dır. (Özüdoğru, 2013). 2013 yılında Türkiye genelinde 2.25 milyon ton pamuk üretim yapılmış olup Kahramanmaraş bölgesinde ise 20859 ton üretim yapılmıştır (Anonim, 2015). Pamuk bitkisinin ülkemiz için öneminin gün geçtikçe artması, pamuk tarımında yüksek verimin ve kalitenin arttırılması öncelik kazanmaya başlamıştır. 
Mobley ve ark. (2000), ultra dar sira pamuk ekiminin yabancı ot kontrolü ve pamuk verimi üzerine etkisini araştırdıkları çalışmada $20 \mathrm{~cm}$ (dar sıra) ve $76 \mathrm{~cm}$ (normal sıra) sıra arası mesafelerini kullanmışlardır. Çalışmada normal sıra arası ekimlerde verimin daha yüksek olduğunu ve verimlerin çeşitlere göre değiştiğini bildirmişlerdir. Gerik (1999), normal (76 $\mathrm{cm})$, geniş $(100 \mathrm{~cm})$ ve dar sira $(51 \mathrm{~cm})$ ekim yöntemlerini araştırdıkları çalışmada, dar sıra ekim yönteminin \%40-100 arasında değişen oranlarda ürün artışına neden olabileceğini belirtmiştir.

$\mathrm{Su}$, ulusal ve uluslararası alanda tarımsal girdiler açısından değerlendirildiğinde en önemli konu olarak ortaya çıkmaktadır (Tanrıverdi, 2005). Dünyanın birçok yerinde su kaynaklarına olan talep her geçen gün hızla artmaktadır. Bu talepleri karşılayabilecek su kaynakları ise kısıtlıdır (Anonim, 2006a). Ülkemizin bulunduğu iklim kuşağı dikkate alındığında sulamanın önemi bir kat daha artmaktadır (Atılgan ve ark., 2010). Ülkemizde yıllık ortalama 40.1 milyar $\mathrm{m}^{3}$ kullanılan suyun 29.6 milyar $\mathrm{m}^{3} \ddot{\mathrm{u}}$ tarımsal sulama, 6.2 milyar $\mathrm{m}^{3} \ddot{\mathrm{u}}$ içme ve kullanma, 4.3 milyar $\mathrm{m}^{3} \ddot{\mathrm{u}}$ ise sanayide kullanılmaktadır (Öztürk, 2009). Türkiye'de kullanılabilir su potansiyelinin yaklaşık olarak \%70 ile tarımsal üretimde kullanılmakta (Atılgan ve ark., 2010) ve sonucunda ise sulama yönetimine ve işletilmesine ilişkin sorunlarda en yoğun olarak bu sektörde karşımıza çıkmaktadır (Anonim, 2006b). Sulama, bir taraftan tarımsal üretimi arttırırken, diğer taraftan gerekli önlemler alınmazsa çevreye zarar vermekte ve doğal dengenin bozulmasina yol açmaktadır (Çakmak ve Gökalp, 2011). Dünya nüfusunun 1950 'de 2.5 milyardan bugün 6.5 milyara gelmesiyle ve artan nüfusun gida gereksinimini karşılamak amacıyla, sulanan alan iki, kullanılan su miktarı da üç katına çıkmıştır (Viala, 2008). Bu durum, artan nüfus ve sanayi ile rekabet halindeki tarımsal sulamanın daha etkin kullanılmasını zorunlu kılmaktadır (Tanriverdi ve Degirmenci, 2011). Pamuk tarımında, sinırlı ve artan fiyatı ile önemli bir girdi olan sulama suyunun maksimum fayda sağlayacak şekilde kullanılması gerekmektedir. $\mathrm{Bu}$ amaçla çalışmada, farklı sıra aralıklarında ekimi yapılan pamuk bitkisinin verim ve uygulanan sulama suyu miktarı üzerine etkisi araştırılarak pamuk yetiştiren çiftçilere rehberlik yapabilecek bir kaynağın ortaya çıkarılması amaçlanmıştır.

\section{MATERYAL ve YÖNTEM}

Araştırma, Kahramanmaraş Tarımsal Araştırma Enstitüsü deneme alanında 2013 yılında yürütülmüştür. Anılan alanın denizden ortalama yüksekliği $700 \mathrm{~m}$ olup $27^{\circ} 11^{\prime}-38^{\circ} 36^{\prime}$ kuzey paralelleri ve $36^{\circ} 15^{\prime}-37^{\circ} 41^{\prime}$ doğu meridyenleri arasında yer almaktadır.

Kahramanmaraş'ın uzun yıllık iklim verileri (19602013) ve 2013 yllına ait verileri Çizelge 1'de verilmiştir. Denemenin yürütüldüğü 2013 yılı iklim değerleri uzun yıllık ortalamalara göre daha sıcak, yağışlı ve daha az nemli geçmiştir. Pamuğun yetişme döneminde ise (Mayıs-Ekim) ortalama sıcaklık değerleri uzun yıllık iklim değerlerinden daha yüksek bulunmuştur (Anonim, 2013)

Çizelge 1. Uzun yıllık (1960-2013) ve deneme yılına (2013) ilişkin iklim verileri

\begin{tabular}{|c|c|c|c|c|c|c|c|}
\hline Yillar & Ölçümler & Mayıs & Haziran & Temmuz & Ağustos & Eylül & Ekim \\
\hline \multirow{5}{*}{ 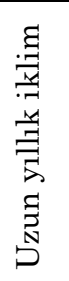 } & Ortalama Nem (\%) & 54.8 & 49.4 & 51.1 & 52.5 & 49.6 & 54.0 \\
\hline & Ortalama Sicaklık $\left({ }^{\circ} \mathrm{C}\right)$ & 20.3 & 25.2 & 28.3 & 28.4 & 25.1 & 19.0 \\
\hline & Minimum Sicaklıkların Ortalaması $\left({ }^{\circ} \mathrm{C}\right)$ & 14.1 & 18.8 & 22.0 & 22.1 & 18.3 & 12.8 \\
\hline & Maksimum Sicaklıkların Ortalaması $\left({ }^{\circ} \mathrm{C}\right)$ & 26.7 & 31.9 & 35.5 & 35.9 & 32.4 & 26.0 \\
\hline & Toplam Yağış Ortalaması (mm) & 40.4 & 6.7 & 1.1 & 0.8 & 7.2 & 45.4 \\
\hline \multirow{5}{*}{ 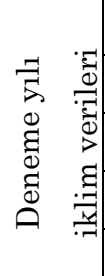 } & Ortalama Nem (\%) & 53.4 & 43.9 & 38.8 & 36.1 & 44.4 & 37.7 \\
\hline & Ortalama Sicaklık $\left({ }^{\circ} \mathrm{C}\right)$ & 22.4 & 25.4 & 30.9 & 32 & 27.3 & 17.3 \\
\hline & Minimum Sicaklıkların Ortalaması $\left({ }^{\circ} \mathrm{C}\right)$ & 16.4 & 19.7 & 22.9 & 23.1 & 19.1 & 11.4 \\
\hline & Maksimum Sıcaklıkların Ortalaması $\left({ }^{\circ} \mathrm{C}\right)$ & 28.6 & 32.5 & 36 & 37.3 & 29.5 & 24.9 \\
\hline & Toplam Yağış (mm) & 76.5 & 16.3 & 0.7 & 0 & 37.5 & 35.1 \\
\hline
\end{tabular}

Deneme alanında her parseli temsil edecek şekilde 12 noktadan Auger-hole yöntemi ile toprak örnekleri alınmış ve belirlenen parametreler ve bazı toprak özellikleri Çizelge 2'de verilmiştir.

Denemede kullanılan sulama suyu, Kahramanmaraş
Tarımsal Araştırma Enstitüsü'nde tesis edilmiş kuyudan alınmış ve yapılan analiz sonucunda sulama suyu kalite sınıfi $\mathrm{C}_{2} \mathrm{~S}_{1}$ olarak KSÜ, Ziraat Fak., Biyosistem Mühendisliği Bölüm laboratuvarında belirlenmiştir (Çizelge 3). 
Çizelge 2. Deneme alanı topraklarının bazı fiziksel ve kimyasal özellikleri

\begin{tabular}{|c|c|c|c|c|c|c|c|c|c|c|c|c|}
\hline \multirow[t]{2}{*}{$\begin{array}{c}\text { Toprak } \\
\text { Katmanı }\end{array}$} & \multirow[t]{2}{*}{$\begin{array}{l}\text { Bünye } \\
\text { Sinifi }\end{array}$} & \multirow{2}{*}{$\begin{array}{l}\text { TK } \\
\text { Pw } \\
(\%)\end{array}$} & \multirow{2}{*}{$\begin{array}{l}\text { SN } \\
\mathrm{Pw} \\
(\%)\end{array}$} & \multirow[t]{2}{*}{$\begin{array}{c}\text { As } \\
\left(\mathrm{gr} / \mathrm{m}^{3}\right)\end{array}$} & \multirow[t]{2}{*}{$\mathrm{pH}$} & \multicolumn{4}{|c|}{$\begin{array}{c}\text { Katyonlar } \\
\text { (me/lt) }\end{array}$} & \multicolumn{3}{|c|}{$\begin{array}{c}\text { Anyonlar } \\
\text { (me/lt) }\end{array}$} \\
\hline & & & & & & $\mathrm{Na}^{+}$ & $\mathrm{K}^{+}$ & $\mathrm{Ca}^{++}$ & $\mathrm{Mg}^{++}$ & $\mathrm{HCO}_{3}$ & $\mathrm{CL}$ & $\mathrm{SO}_{4}$ \\
\hline $0-30$ & $\mathrm{SC}$ & 26.37 & 14.68 & 1.47 & 7.45 & 0.43 & 0.09 & 1.53 & 1.31 & 1.52 & 1.28 & 0.56 \\
\hline $30-60$ & $\mathrm{SC}$ & 26.62 & 14.49 & 1.46 & 7.53 & 0.49 & 0.07 & 1.62 & 1.53 & 1.49 & 1.08 & 1.14 \\
\hline $60-90$ & $\mathrm{SC}$ & 26.83 & 14.52 & 1.49 & 7.69 & 0.52 & 0.11 & 1.59 & 1.55 & 1.52 & 1.06 & 1.19 \\
\hline
\end{tabular}

Çizelge 3. Sulama suyu analiz sonuçları

\begin{tabular}{|c|c|c|c|c|c|c|c|c|c|c|c|}
\hline \multirow{2}{*}{$\begin{array}{c}\text { Suyun } \\
\text { Sinifi }\end{array}$} & \multirow{2}{*}{$\begin{array}{c}\text { EC } \\
(\mathrm{dS} / \mathrm{m})\end{array}$} & \multirow{2}{*}{$\begin{array}{l}\mathrm{Na} \\
(\%)\end{array}$} & \multirow{2}{*}{$\mathrm{pH}$} & \multicolumn{4}{|c|}{ Katyonlar (me/lt) } & \multicolumn{4}{|c|}{ Anyonlar (me/lt) } \\
\hline & & & & $\mathrm{Na}^{+}$ & $\mathrm{K}^{+}$ & $\mathrm{Ca}^{++}$ & $\mathrm{Mg}^{++}$ & $\mathrm{CO}_{3}^{-}$ & $\mathrm{HCO}_{3}$ & $\mathrm{Cl}^{-}$ & $\mathrm{SO}_{4}$ \\
\hline $\mathrm{C}_{2} \mathrm{~S}_{1}$ & 0.327 & 19 & 7.0 & 0.35 & 0.05 & 1.83 & 1.79 & - & 1.2 & 0.71 & 2.2 \\
\hline
\end{tabular}

Denemede Erşan-92 pamuk çeşidi kullanılmıştır. Tohumlar araziye pnömatik ekim mibzeri ile ekilerek sira arası mesafe 50, 70 ve $90 \mathrm{~cm}$ ve sira üzeri ise her sıra arası mesafe için aynı $20 \mathrm{~cm}$ olacak şekilde ayarlanmıştır. Denemedeki bitkilere verilecek olan 15 $\mathrm{kg} / \mathrm{da}$ azotlu gübrenin yarısı ekimle beraber, geriye kalan kısmı ise çiçeklenme başlangıcında uygulanmıştır. Çalışmada, pamuk bitkisinin ekim tarihi 12 Mayıs hasat zamanı ise 19 Eylül ve 15 Ekim tarihlerinde yapılmıştır. Araştırmada kullanılan damla sulama sisteminin projelendirilmesi Yıldırım ve ark. (2004)'e göre yapılmıştır ve $75 \mathrm{~mm}$ çapında mandallı PVC ana boru ile $33 \mathrm{~cm}$ aralıklarla debisi 1 atm basınçta $4 \mathrm{~L} / \mathrm{h}$ olan içten geçik damlatıcıların yer aldığı $16 \mathrm{~mm}$ çapında $\mathrm{PE}$ lateral borular kullanılmıştır. Lateral borulardaki işletme basıncı kullanılan regülatör yardımıyla 1 atm'in altına düşürülmemeye çalışılmıştır. Konulara uygulanan sulama suyu miktarı ise ana boruya bağlanan sayaç yardımıyla ölçülendirilmiştir.

Deneme alanındaki her konunun üç farklı derinliğinden (0-30, 30-60 ve 60-90) toprak örnekleri alınmış ve kuru ağırlık yüzdesine göre nem içeriği belirlenmiştir. Daha sonra bu değerlere göre sulama zamanı ve sulama suyu miktarları hesaplanmıştır. Mevcut nemi tarla kapasitesine getirecek sulama suyu miktarı Eşitlik 1 kullanılarak hesaplanmıştır (Güngör ve ark., 2002).

$\mathrm{d}_{n}=\frac{\left(\mathrm{P}_{\mathrm{w}(\mathrm{TK})}-\mathrm{P}_{\mathrm{w}(\mathrm{MN})}\right)}{100} \times A_{s} \times D \times R_{y}$

Eşitlikte; $\mathrm{d}_{n}$, verilen sulama suyu miktarı $(\mathrm{mm}) ; \mathrm{P}_{\mathrm{w}(\mathrm{TK}) \text {, }}$ kuru ağırlık yüzdesi cinsinden tarla kapasitesi g/g (\%); $\mathrm{P}_{\mathrm{w}(\mathrm{MN})}$ kuru ağırlık yüzdesi cinsinden solma noktası $\mathrm{g} / \mathrm{g}$

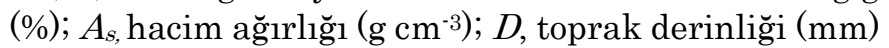
ve $R_{y}$, kullanilabilir su tutma kapasitesinin tüketilmesine izin verilen miktarı (\% 50)'dır. Eşitlikte sulama suyu miktarı $\left(\mathrm{d}_{n}\right)$, her bir konu için ayrı ayrı hesaplanmıştır. Etkili kök derinliğinde eksik nem her sulamada tarla kapasitesine getirilmiş, bu amaçla her sulamada tarla kapasitesine getirilene kadar sulama suyu uygulanmıştır.

Farklı sıra arası mesafelerin verim üzerine etkilerini belirlemek amacıyla her uygulama için 3 tekerrür yer almıştır. Çalışmada, kenar etkisini ortadan kaldırmak amacıyla örnekler parsellerin ortasından alınmıştır. Denemeden elde edilen veriler JMP istatistik paket programı kullanılarak varyans analizine tabi tutulmuş, uygulamalar arasındaki farklılıklar LSD çoklu karşılaştırma testine göre değerlendirilmiştir.

\section{BULGULAR ve TARTIŞMA}

Çalışmada gözlem parsellerinden elde edilen nem değerinin \%50'si tüketildiğinde sulama zamanı belirlenmiştir. Diğer konular da ise control konusunun sulama zamanına göre 0-90 cm'lik toprak katmanını tarla kapasitesine tamamlayacak şekilde sulama yapılmıştır. En yüksek sulama suyu miktarı $622 \mathrm{~mm}$ ile $70 \mathrm{~cm}$ sıra aralığa sahip normal ekim konusuna, $589 \mathrm{~mm}$ sulama suyu $50 \mathrm{~cm}$ dar aralıklı sira ekim konusuna ve en düşük sulama suyu miktarı ise 555 $\mathrm{mm}$ ile $90 \mathrm{~cm}$ aralıklı geniş sıra ekim konusuna uygulanmıştır (Çizelge 4). Araştırmada uygulanan sulama suyu miktarları ile Yılmaz ve ark. (2005), Sarı ve Dağdelen (2010) ve Ertek ve Kanber (2002) tarafından yapılan çalışmalardan elde edilen değerler arasında benzer sonuçlar elde edilmiştir.

Sulama suyu kullanım randımanı değerleri 50,70 ve $90 \mathrm{~cm}$ sıra aralığ $0.68 \mathrm{~kg} / \mathrm{m}^{3}$ olarak hesaplanmıştır. En yüksek sulama suyu kullanım randımanı $0.95 \mathrm{~kg} / \mathrm{m}^{3}$ ile normal sıra ekim yapılan $70 \mathrm{~cm}$ konusundan, en düşük ise 0.68 $\mathrm{kg} / \mathrm{m}^{3}$ olarak $90 \mathrm{~cm}$ aralıklı konudan elde edilmiştir. Elde edilen bulgular önceki araştırıcıların yaptıkları çalışmalar ile benzerlik göstermiştir (Yazar ve ark., 2002; Ertek ve Kanber, 2002).

Konulara göre uygulanan sulama suyu miktarı üzerine yapılan varyans analiz sonucunda farklı sıra arası mesafeleri konularına uygulanan sulama suyu miktarları arasında $(\mathrm{p}<0.01)$ önem düzeyinde önemli bulunmuştur (Çizelge 5.). 
Çizelge 4. Konulara göre uygulanan sulama suyu miktarı ve sulama suyu kullanım randımanı

\begin{tabular}{cccc}
\hline Konular & Sulama Sayısı & Sulama suyu Miktarı $(\mathrm{mm})$ & $\begin{array}{c}\text { Sulama Suyu Kullanım } \\
\text { Randımanı }\left(\mathbf{k g} / \mathbf{m}^{3}\right)\end{array}$ \\
\hline 50 & 10 & 589 & 0.80 \\
70 & 10 & 622 & 0.95 \\
90 & 10 & 555 & 0.68 \\
\hline
\end{tabular}

Çizelge 5. Farklı sıra arası mesafelerin sulama suyu miktarı üzerine etkisine ilişkin varyans analiz sonuçları

\begin{tabular}{lccccc}
\hline \multicolumn{1}{c}{ Kaynaklar } & SD & KT & KO & F Ratio & ÖD \\
\hline Sira arası mesafe & 2 & 200,066 & 100,033 & 69,3778 & $<.0001$ \\
Tekerrür & 2 & 0,6 & 0,3 & 0,1418 & 0,8681 \\
Hata & 58 & 122,7333 & 2,1161 & & \\
\hline
\end{tabular}

Calışmada kütlü verim değerlerine bakıldığında dar $(50 \mathrm{~cm})$, normal $(70 \mathrm{~cm})$ ve geniş $(90 \mathrm{~cm})$ sıra ekimlerine sahip konularda sirasiyla $471.2 \mathrm{~kg} \mathrm{da}^{-1}$, $595.6 \mathrm{~kg} \mathrm{da}^{-1}$ ve $378.6 \mathrm{~kg} \mathrm{da}^{-1}$ kütlü verim değerleri elde edilmiştir (Çizelge 6.). Normal sıra ekim sıklığında dar ve geniş sıra ekim sıkılığına göre çok daha yüksek verim elde edildiği görülmüştür. Normal sıra ekim yönteminde ayrıca mekanize etmesi ve kültürel işlemleri daha kolaylaştırdığı için tercih edilebileceği söylenebilir. McCarty ve ark. (1993) yaptıkları bir çalışmada dar sıra pamuk ekiminin birim alan verim değerlerini arttırdığını, Gerik (1999), normal $(76 \mathrm{~cm})$, geniş $(100 \mathrm{~cm})$ ve dar sıra $(51 \mathrm{~cm})$ ekim yöntemlerini araştırdıkları çalışmada, dar sıra ekim yönteminin \%40-100 arasında değişen oranlarda ürün artışına neden olabileceğini vurgulamışlardır. Ancak Özdemir (2007), yaptığı çalışmasında çeşitlerin ekim sıklığı uygulamalarına tepkilerinin farklı olduğunu bildirmiş ve Delta Opal, Golden West ve Maraş-92 çeşitlerinin normal ekimde daha yüksek verim verdiklerini belirtmiştir. Elde edilen verim değerleri ile diğer araştırıcıların (Sarı ve Dağdelen, 2010; Yazar ve ark., 2002; Dağdelen ve ark., 2005) yaptıkları çalışmalar ile paralellik göstermektedir.

Çizelge 6. Farklı sıra arası mesafelerinin pamuk verimi ve bitki boyu değerleri

\begin{tabular}{ccc}
\hline Konular & Bitki Boyu (cm) & Verim (kg/da) \\
\hline 50 & 60 & 471.2 \\
70 & 75 & 595.6 \\
90 & 61 & 378.6 \\
\hline
\end{tabular}

Farklı ekim sıklıklarının pamuk bitkisi boyu üzerine etkisine incelendiğinde dar $(50 \mathrm{~cm})$, normal $(70 \mathrm{~cm})$ ve geniş sıra $(90 \mathrm{~cm})$ ekim aralıklarında sırasıyla $60 \mathrm{~cm}$, $75 \mathrm{~cm}$ ve $61 \mathrm{~cm}$ uzunluklar ölçülmüştür (Çizelge 6). Özdemir (2007), yaptığı çalışmada çeşitlerin bitki boyu yönünden farklı ekim sıklığı konularına tepkilerinin farklı olduğunu belirtmiş ve bitki boyu değerlerinin $52.33 \mathrm{~cm}$ ile $100.13 \mathrm{~cm}$ arasında bulmuştur. Nicholas ve ark. (2004) pamuk bitkisinde dar sira ekim sıklığının bitki boyunu azalttığını bildirmişlerdir. Çalışmamızda ise verim değerlerine ile paralel olarak bitki boyunda en yüksek $70 \mathrm{~cm}$ normal sıklıkta ekim yapılan konuda elde edildiğini en düşük değerin ise 50 cm dar sıra ekimde konuda elde edilmiştir.
Çalışmamızda elde edilen bitki boyu değerler birçok araştırıcının yapmış oldukları çalışmalarda benzer sonuçları bildirmişlerdir (Gill ve Singh, 1982; Başbağ, 2005; Kaya ve ark., 2011).

Konulara göre kütlü verim değerleri üzerine yapılan varyans analiz sonucunda farklı sira arası mesafeleri konularının kütlü verim değerleri arasında $(\mathrm{p}<0.01)$ önem düzeyinde önemli bulunmuştur (Çizelge 7.)

Farklı ekim sıklıklarının bitki boyu üzerine olan etkilerini belirlemek amaciyla yapılan varyans analiz sonucunda elde edilen sonuçlar Çizelge 8'de verilmiştir. Çizelgeden de anlaşılacağı üzere çalışmada sıra arası mesafelerinin bitki boyu üzerine etkisi istatiksel olarak önemli bulunmuştur $(\mathrm{p}<0.01)$.

Çizelge 7. Farklı sıra arası mesafelerin kütlü verim üzerine etkisine ilişkin varyans analiz sonuçları

\begin{tabular}{lccccc}
\hline Kaynaklar & SD & KT & KO & F Ratio & ÖD \\
\hline Sira arası mesafe & 2 & 213417,36 & 106708,68 & 3097994 & $<.0001$ \\
Tekerrür & 2 & 0,07 & 0,035 & 1,000 & 0,3874 \\
Sira arası mesafe*tekerrür & 4 & 0,27 & 0,067 & 1,967 & 0,1428 \\
Hata & 18 & 0,62 & 0,344 & & \\
\hline
\end{tabular}


Çizelge 8. Farklı sıra arası mesafelerin bitki boyu üzerine etkisine ilişkin varyans analiz sonuçları

\begin{tabular}{lccccc}
\hline Kaynaklar & SD & KT & KO & F Ratio & ÖD \\
\hline Sira arası mesafe & 2 & 2280,0000 & 1140,000 & 637,2671 & $<.0001$ \\
Tekerrür & 2 & 0,400 & 0,200 & 0,1118 & 0,8945 \\
Sira arası & 4 & 96,4000 & 24,100 & 13,4720 & $<.0001$ \\
mesafe*tekerrür & & & & & \\
Hata & 36 & 64,4000 & 1,789 & & \\
\hline
\end{tabular}

\section{SONUÇ}

Elde edilen sonuçlara göre farklı sıra aralıklarında tüm verim değerleri ülkemiz ortalaması olan $176 \mathrm{~kg}$ $\mathrm{da}^{-1}$ 'dan yüksek ve en yüksek verim değeri de normal sıra ekim $(70 \mathrm{~cm})$ yapılan konudan $595.6 \mathrm{~kg} \mathrm{da}{ }^{-1}$ olmak üzere elde edilmiştir. En düşük kütlü pamuk verimi ise $378.6 \mathrm{~kg} \mathrm{da}^{-1}$ ile geniş sira ekim $(90 \mathrm{~cm})$ konusundan elde edilmiştir. Uygulanan sulama suyu miktarları konulara göre $555 \mathrm{~mm}$ ile $622 \mathrm{~mm}$ arasında değiştiği görülmüştür. Sulama suyu kullanım randımanları incelendiğinde en yüksek değerin normal sira ekim $(70 \mathrm{~cm})$ yapilan konuda $0.95 \mathrm{~kg} \mathrm{~m}^{-3}$ elde edilmiştir. İstatistiksel açıdan farklı sıra aralıkları konularında uygulanan sulama suyu miktarları ve kütlü verim değerleri arasındaki ilişkiler önemli bulunmuştur. Çalışmada, pamuk yetiştiriciliğinde normal sıra ekimin $(70 \mathrm{~cm})$ diğer konular (50 ve $90 \mathrm{~cm}$ ) ile kıyaslandığında; optimum su kullanımı sağlandığında pamuk bitkisinin kütlü verimine ve vejetatif gelişimine olumlu etkileri olacağ sonucuna varılmıştır.

\section{KAYNAKLAR}

Anonim 2006a WCA. 2006a. http://www.wcainfonet.org/servlet/ (Erişim tarihi: 19.11.2014).

Anonim 2006b. Southernland Association, 2006. http:// www.Terredelsud.Org/risidriceng.php (Erişim tarihi:15.05.2015).

Anonim 2013. Kahramanmaraş Devlet Meteoroloji İşleri Bölge Müdürlüğü. 2013.

Anonim 2015. Türkiye İstatistik Kurumu Veriler 2015. http://www.Tuik.Gov.Tr. (Erişim tarihi:11.05.2015).

Atılgan A, Özdemir Ö, Öz H, Kadayıfçı A, Şenyiğit U, 2010. Isparta Yöresindeki Meyve Bahçelerinde Kullanılan Sulama Yöntemlerinin Analizi. Süleyman Demirel Üniversitesi Ziraat Fakültesi Dergisi 5(2): 2732.

Başbağ S, 2005. Inter-spesifik (G. Hirsutum L. x G. Barbadense L.) Hibrit Pamuklarm Diyarbakır Koşullarında Yetiştirilme Olanakları. Türkiye VI. Tarla Bitkileri Kongresi Bildiriler(I): 325-330. 5-9 Eylül 2005, Antalya.

Çakmak B, Gökalp Z, 2011. İklim Değişikliği ve Etkin Su Kullanımı, Tarım Bilimleri Araştırma Dergisi 4 (1): 8795.

Dağdelen N, E Yılmaz F, Sezgin T, Gürbüz 2005. Karık Yöntemiyle Sulanan Pamukta Farkl Sulama Düzeylerinin Kütlü Kalitesi Ve Bazı Agronomik
Özellikler Üzerinde Etkisi. IV. Gap Tarım Kongresi Bildiriler:1651-1658.21-23 Eylül 2005, Şanlıurfa.

Ertek A, Kanber R, 2002. Damla Sulama Yöntemiyle Uygulanan Farklı Sulama Programlarının Pamuk Çırçır Randımanına Etkileri. KSÜ Fen ve Mühendislik Dergisi 5(1) 118-130.

Gerik TJ, 1999. Ultra-Narrow Row Cotton Performance Under Drought Conditions Reprinted from The Proceedings of the Belt Wide Cotton. Conference Volume 1:581.

Gill SS, Singh TH, 1982. Stability For Fibre and Morphological Characters in Upland Cotton. Indian Journal of Genetics and Plant Breeding. 41 (2): 292296.

Güngör Y, Erözel AZ, Yıldırım O, 2002. Sulama. Ankara Üniversitesi Ziraat Fakültesi Yayınları: 1443, Ders Kitabı: 424, Ankara.

Gürel A, Akdemir H, Emiroğlu Ş H, Kadoğlu H, Karadayı, H B. 2000. Türkiye lif bitkileri. Tarım Haftası 2000 Türkiye Ziraat Mühendisliği V. Teknik Kongresi (1721 Ocak). Milli Kütüphane, Ankara.

Kaya AR, Eryiğit T, Arslan B, 2011. Kahramanmaraş Koşullarında Bazı Pamuk (Gossypium hirsutum L. ve Gossypium barbadense L.) Çeşitlerinin Ve Türler Arası Melezlemelerle Elde Edilen Hatların (G. hirsutum L. X G. barbadense L.) Verim, Verim Unsurlarinin Belirlenmesi. Iğdır Üniversitesi. Fen Bilimleri Enstitüsü Dergisi 1(2): 97-105.

Mccarty, W. H., Mccarty, J. C., Jenkins, J. N., 1993. Fruiting Characteristics of Narrow Row Cotton Grown in Mississippi in 1992. Proceedings Belt Wide Cotton Conferences, p. 1271.

Mobley M L, Burgeros N R, Mccelland M R., 2000. Weed Control And Yield Performance of Transgenic Cotton in Ultra Narrow Rows. Reprinted From the Proceedings of the Belt Wide Cotton Conference, 2:1491-1492.

Nicholas, S.P., Charles, E. Snipes, and Michael A. Jones 2004. Cotton Growth, Lint Yield, And Fiber Quality As Affected By Row Spacing And Cultivar. The Journal of Cotton Science 8:1-12 .

Özdemir M, 2007, Buğday Sonrası İkinci Ürün Pamuk Üretiminde Ekim Siklığının Verim Ve Lif Teknolojik Özelliklere Etkisi.(Yüksek Lisans Tezi). K.S.U. Fen Bilimleri Enstitüsü Tarla Bitkileri Bölümü.

Öztürk M, 2009. Havza Esash Entegre Su Yonetimi, TBMM Cevre Komisyonu. Ankara.

Özüdoğru T, Çakaryıldırım N, 2006. Pamuk durum ve tahmin: 2005/2006, Tekstil ve Mühendis, Tekstil 
Mühendisleri Odası Yayını, Ocak 2006, Sayı:61.

Özüdoğru T, 2013. Durum ve Tahmin Pamuk. 2011-2012. Tarımsal Ekonomi ve Politika Geliştirme Enstitüsü. Ankara.

Sarı Ö, Dağdelen N, 2010. Damla Sulama Yöntemiyle Sulanan Pamukta Farklı Lateral Aralıklarının Pamuk Su-Verim İlişkileri Üzerine Etkisi ADÜ Ziraat Fakültesi Dergisi; 7(1) : 41-48.

Tanriverdi Ç, 2005. Using TDR in the Agricultural Water Management. KSÜ. Fen ve Mühendislik Dergisi, 8(2):108-115.

Tanriverdi C, Degirmenci, H, 2011. Assessment of Management Transfer of Kahramanmaraş Irrigation System. Scientific Research and Essays, Vol. 6(3):522528.

Viala E, 2008. Water For Food Water For Life. A
Comprehensive Assessment of Water Management in Agriculture. International Water Management Institute. 645p., Earthscan, USA.

Yazar A, Sezen SM, Sesveren S, 2002. Lepa and Trickle Irrigation of Cotton in The Southest Anatolia Project (GAP) Area in Turkey. Agricultural Water Management .(3), 129-203.

Yıldırım, O., Erözel A., Z. ve Güngör, Y., 2004. Ankara Üniversitesi Ziraat Fakültesi Tarımsal Yapılar ve Sulama Bölümü. Sulama Kitabı Yayın No:1540 Ders Kitabı:493 Ankara, 20-124s.

Yllmaz, E., Dağdelen, N., Sezgin, F., Gürbüz, T., 2005.Aydın Koşullarında Farklı Sulama Yöntemleri ve Sulama Programlarının Pamukta Kütlü Kalitesi Üzerine Etkisi. ADÜ Ziraat Fakültesi Dergisi; 2(1): 1722. 